\title{
Radical Cyclopolymerization of Divinyl Acetals-Structure Variation with Polymerization Conditions ${ }^{\dagger}$
}

\author{
Mitsuo Tsukino and Toyoki KunITAKE* \\ Department of Chemical Engineering, Kitakyushu Technical College, \\ Kokuraminami, Kitakyushu 803, Japan \\ *Department of Organic Synthesis, Faculty of Engineering, \\ Kyushu University, Fukuoka 812, Japan
}

(Received October 11, 1984)

\begin{abstract}
Radical polymerizations of divinyl formal, acetaldehyde divinyl acetal, and acetone divinyl acetal were conducted under a series of conditions, and the microstructures of the cyclopolymers obtained were examined by ${ }^{1} \mathrm{H}$ NMR and ${ }^{13} \mathrm{C}$ NMR spectroscopies. The cyclopolymers contained cis-dioxolane units as the major structure along with other minor structures such as the pendant dioxolane unit and trans-dioxolane unit. The content of the major structure increased with lowering polymerization temperature and increasing monomer concentration. The uncyclized unit and the six-membered dioxane ring were not formed under any condition. The propagation steps included cyclization and isomerization in addition to monomer addition and are discussed on the basis of variation in polymer structure with polymerization conditions. The methyl substitution at the acetal carbon lowers isomerization of the cyclized radical.
\end{abstract}
KEY WORDS
NMR Spectroscopy
Poly(divinyl
formal)
Poly(acetaldehyde divinyl acetal) / Poly(acetone divinyl acetal) /
Cyclopolymerization / Steric Structure /

It has been established in the past decade that head-to-head (five-membered ring) cyclopolymers are formed by radical polymerization of non-conjugated dienes such as divinyl ethers, ${ }^{1-4}$ diallylamines, ${ }^{5,6}$ allyl esters of unsaturated acids, ${ }^{7}$ methacrylic anhydride, ${ }^{8}$ and dimethacrylamide. $^{9}$

We studied radical cyclopolymerization of the divinyl acetal family-divinyl formal (DVF), acetaldehyde divinyl acetal $\left(\mathrm{CH}_{3}-\right.$ DVA), and acetone divinyl acetal $\left(2 \mathrm{CH}_{3}-\right.$ DVA) - and found the polymers to be comprized of analogous structural units. ${ }^{10}$

The ${ }^{13} \mathrm{C}$ NMR spectral data indicated the predominant formation of the cis-dioxolane ring (I), along with the pendent dioxolane unit (II) produced by intramolecular hydrogen migration. The connection of the main structure was invariably made of equal amounts of the meso and racemic structures. No uncyclized unit or six-membered (1,3-dioxane) unit or trans-dioxolane units (III and IV) could be detected. These structures (I-IV) are illustrated here for DVF. The same conclusions were obtained for $\mathrm{CH}_{3}$-DVA and $2 \mathrm{CH}_{3}$-DVA.

More recently, for DVF it was observed that trans-dioxolane rings are produced under other polymerization conditions. ${ }^{11} \mathrm{We}$ thus examined the influence of polymerization conditions on the polymer structures of $\mathrm{CH}_{3}$-DVA and $2 \mathrm{CH}_{3}$-DVA and carried out kinetic analyses on the propagation processes of these three monomers.

\footnotetext{
† Contribution No. 753 from Department of Organic Synthesis.

* Address correspondence to this author.
} 

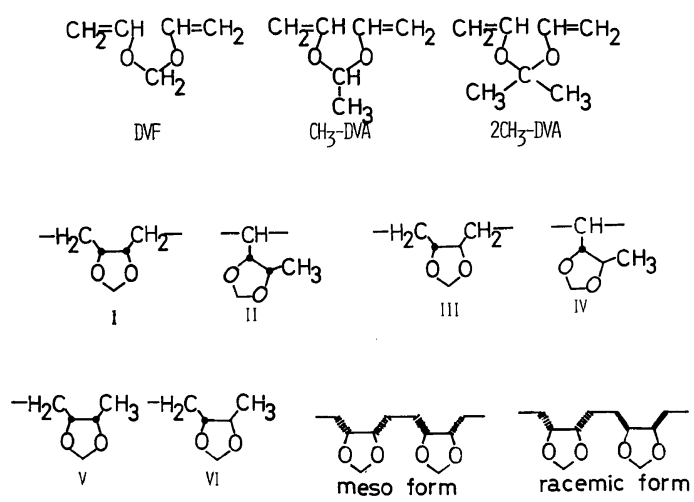

\section{EXPERIMENTAL}

\section{Materials}

Divinyl acetal monomers and 1,3-dioxolanes were prepared as described before. ${ }^{10}$ Azobisisobutyronitrile (AIBN) was recrystallized from methanol. Organic solvents were purified by conventional methods.

\section{Polymerization}

Benzene and toluene were used as solvents for the polymerization at $10-70^{\circ} \mathrm{C}$ and at $-10^{\circ} \mathrm{C}$, respectively. AIBN was used as the initiator at 50 and $70^{\circ} \mathrm{C}$, but irradiation with a 100-W high pressure $\mathrm{Hg}$ lamp was additionally employed for polymerization at temperatures below $30^{\circ} \mathrm{C}$. Given amounts of monomer, solvent, and AIBN were placed in glass ampoules (Pyrex glass ampoules in the case of photoirradiation), which were then subjected to several freeze-pump-thaw cycles and sealed. After polymerization in a constant-temperature bath, the contents were poured into methanol and the recovered polymers were reprecipitated from benzene and methanol. The polymers were freeze-dried if necessary. The conversions were kept below $10 \%$.

\section{Miscellaneous}

Molecular weight was measured with a Toyo Soda HLC-802UR gel permeation chromatograph using monodisperse polystyrenes for calibration. ${ }^{13} \mathrm{C}$ NMR and ${ }^{1} \mathrm{H}$ NMR spectra were obtained using a JEOL FX-100 spectrometer $\left(100 \mathrm{MHz}\right.$ for ${ }^{1} \mathrm{H}$ and $25 \mathrm{MHz}$ for ${ }^{13} \mathrm{C}$ ) under noise decoupling (for ${ }^{13} \mathrm{C}$ ).

The ${ }^{1} \mathrm{H}$ chemical shifts (in $\mathrm{CCl}_{4}$ ) of 1,3dioxolanes used as model compounds of the structural unit in polymers are as follows.

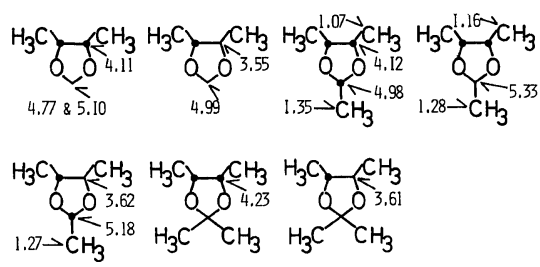

\section{RESULTS AND DISCUSSION}

\section{Poly(divinyl formal)}

The structural variation in poly(divinyl formal) was briefly discussed in the previous paper. ${ }^{11}$ The polymerization data at various

Table I. Radical polymerization of divinyl formal in $\mathrm{C}_{6} \mathrm{H}_{6}$

\begin{tabular}{|c|c|c|c|c|c|c|}
\hline \multirow{2}{*}{$\begin{array}{l}\text { Run } \\
\text { No. }\end{array}$} & Polymn. temp & Monomer & AIBN & Polymn. time & Conversion & \multirow{2}{*}{$M_{n}$} \\
\hline & ${ }^{\circ} \mathrm{C}$ & $\mathrm{moll}^{-1}$ & $\mathrm{moll}^{-1}$ & $\mathrm{~h}$ & $\%$ & \\
\hline $1^{\mathrm{a}}$ & -10 & 5.0 & $5 \times 10^{-2}$ & 15.0 & 7.5 & - \\
\hline $2^{b}$ & 10 & 2.5 & $1 \times 10^{-1}$ & 8.0 & 8.6 & 5500 \\
\hline 3 & 30 & 2.5 & $5 \times 10^{-2}$ & 2.0 & 7.8 & 4500 \\
\hline 4 & 50 & 2.5 & $1 \times 10^{-2}$ & 20.0 & 7.0 & 14000 \\
\hline $5^{\mathrm{b}}$ & 70 & 2.5 & $2 \times 10^{-2}$ & 1.5 & 8.1 & 8100 \\
\hline
\end{tabular}

a Polymerized in toluene.

b From ref 11. 


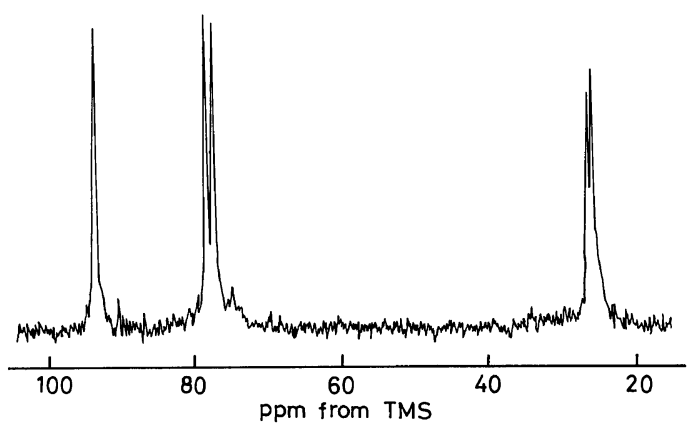

Figure 1. ${ }^{13} \mathrm{C}$ NMR spectrum of poly(divinyl formal). Sample: Table I, run No. $1 ; 27 \mathrm{w} / \mathrm{v} \% \mathrm{C}_{6} \mathrm{D}_{6}$ at $75^{\circ} \mathrm{C}$; accumulation, 1000 scans.

temperatures are summarized in Table I. The molecular weights are relatively small. The polymer structure becomes more regular as the polymerization temperature is lowered. Figure 1 shows the ${ }^{13} \mathrm{C}$ NMR spectrum of the polymer obtained at $-10^{\circ} \mathrm{C}$. The spectrum consists of the main-chain methylene carbon(26$27 \mathrm{ppm}$ ), the ring methine carbon (77-79 ppm) and the acetal carbon (94 ppm). These peaks were assigned to the carbons of the main structure I, and the other peaks assignable to the minor structures were absent. The splitting (doublets) of the main-chain methylene carbon and ring methine carbon is attributed to the meso and racemic connections of the main structural unit. ${ }^{10,11}$ It is concluded that the polymer obtained at low temperatures possesses a very regular structure. The decrease in the secondary structures with increasing monomer concentrations has been mentioned before. $^{11}$

\section{Poly(acetaldehyde divinyl acetal)}

The polymerization results of acetaldehyde divinyl acetal are summarized in Table II. The molecular weights are higher than those of poly(divinyl formal) given in Table I. Figure 2 compares ${ }^{1} \mathrm{H}$ NMR spectra of the polymers obtained at different temperatures. The presence of structural units VII and VIII was confirmed from the analysis of ${ }^{13} \mathrm{C}$ NMR spectra. ${ }^{10}$ However, as with poly(DVF), the
Table II. Radical polymerization of acetaldehyde divinyl acetal

\begin{tabular}{|c|c|c|c|c|c|}
\hline \multirow{2}{*}{$\begin{array}{l}\text { Run } \\
\text { No. }\end{array}$} & $\begin{array}{l}\text { Polymn. } \\
\text { temp }\end{array}$ & AIBN & $\begin{array}{c}\text { Polymn. } \\
\text { time }\end{array}$ & Conversion & \multirow{2}{*}{$M_{n}$} \\
\hline & ${ }^{\circ} \mathrm{C}$ & $\mathrm{moll}^{-1}$ & $\mathrm{~h}$ & $\%$ & \\
\hline 1 & -10 & $5 \times 10^{-2}$ & 19.0 & 8.8 & 11000 \\
\hline 2 & 10 & $2 \times 10^{-1}$ & 0.5 & 6.4 & 8600 \\
\hline 3 & 30 & $5 \times 10^{-2}$ & 0.6 & 8.7 & 18000 \\
\hline 4 & 50 & $2 \times 10^{-2}$ & 7.0 & 6.0 & 30000 \\
\hline 5 & 70 & $2 \times 10^{-2}$ & 0.5 & 6.0 & 26000 \\
\hline
\end{tabular}

${ }^{a}[\mathrm{M}]=5.0 \mathrm{moll}^{-1}$. Solvent, toluene for run 1 and benzene for runs $2-5$.

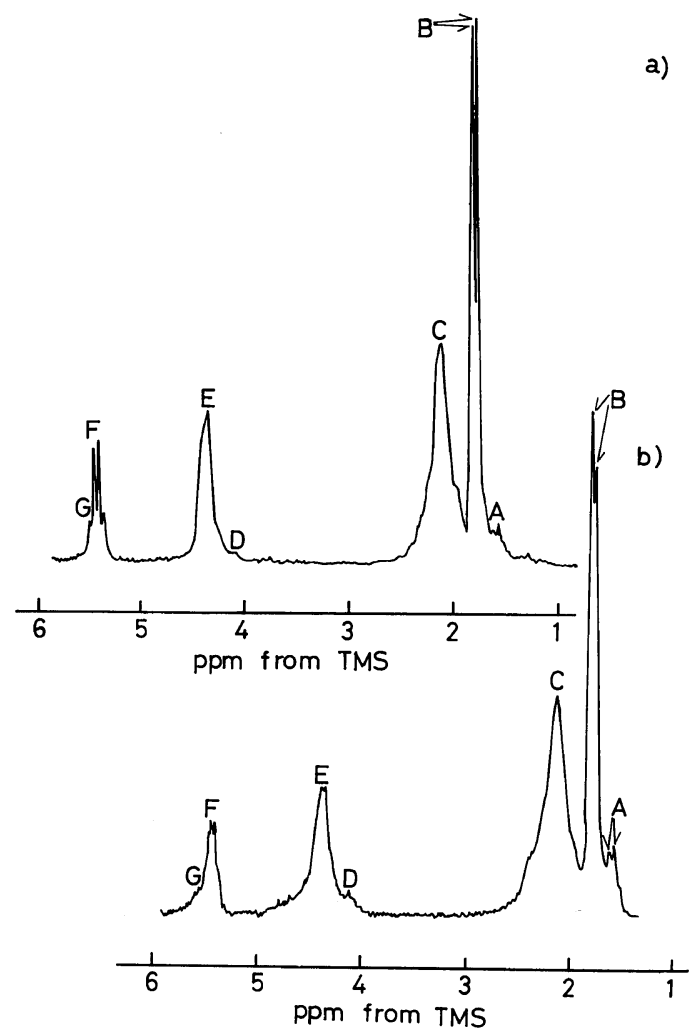

Figure 2. ${ }^{1} \mathrm{H}$ NMR spectra of poly(acetaldehyde divinyl acetal). a) Sample: Table II, run No. $1.3 \mathrm{w} / \mathrm{v} \%$ in $\mathrm{C}_{6} \mathrm{D}_{6}+o-\mathrm{C}_{6} \mathrm{H}_{4} \mathrm{Cl}_{2}$ at $140^{\circ} \mathrm{C}$; accumulation, 64 scans. b) Sample: Table II, run No. 5. $3 \mathrm{w} / \mathrm{v} \%$ in $\mathrm{C}_{6} \mathrm{D}_{6}+o-$ $\mathrm{C}_{6} \mathrm{H}_{4} \mathrm{Cl}_{2}$ at $140^{\circ} \mathrm{C}$.

trans ring structures $\mathbf{I X}$ and $\mathbf{X}$ could be formed by the proper selection of polymerization conditions. From comparisons with ${ }^{1} \mathrm{H}$ NMR 


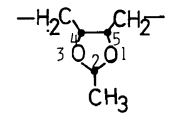

VII

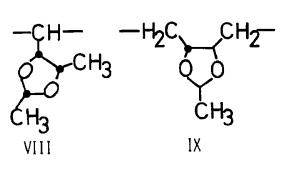

data of 1,3-dioxolanes (model compounds), the following assignments were made for the NMR spectra of Figure 2.

A (doublet), $1.60 \mathrm{ppm}$; acetal methyl proton in $\mathbf{X}$ and 5-methyl proton in VIII.

B (doublet), 1.75 ppm; acetal methyl proton in VII.

C, $2.12 \mathrm{ppm}$; exocyclic methylene and methine proton of all units.

$\mathrm{D}, 4.12 \mathrm{ppm}$; ring methine proton at the 4 and 5 positions in IX.

E, $4.36 \mathrm{ppm}$; ring methine proton at the 4 and 5 positions in all units other than IX.

F (doublet), $5.41 \mathrm{ppm}$; acetal methine proton in VII and VIII.

G, 5.57 ppm; acetal methine proton in IX.

The chemical shifts for the polymer protons are $0.1-0.5 \mathrm{ppm}$ larger than those of the corresponding protons of the model compounds. These differences probably arise from differences in the NMR solvents $\left(\mathrm{CDCl}_{3}\right)$ for the model compounds and mixtures of $\mathrm{C}_{6} \mathrm{D}_{6}$ and $o$-dichlorobenzene for the polymers) and/or from different magnetic environments due to neighboring units of the polymer.

Since Figure $2 b$ is less simple than Figure $2 a$, it is clear that the polymer obtained at a high temperature $\left(70^{\circ} \mathrm{C}\right.$ in this case) contains larger amounts of the minor structures. The abovementioned assignments indicate that the polymer obtained at $-10^{\circ} \mathrm{C}$ is made predominantly of structure VII and that other minor structures VIII, IX and $\mathbf{X}$ increase with increasing polymerization temperature.

Figure 3 gives the ${ }^{13} \mathrm{C}$ NMR spectra of poly(acetaldehyde divinyl acetals) prepared under contrasting polymerization conditions. The spectral assignments have been reported. ${ }^{10}$ The polymer obtained with a high mo-

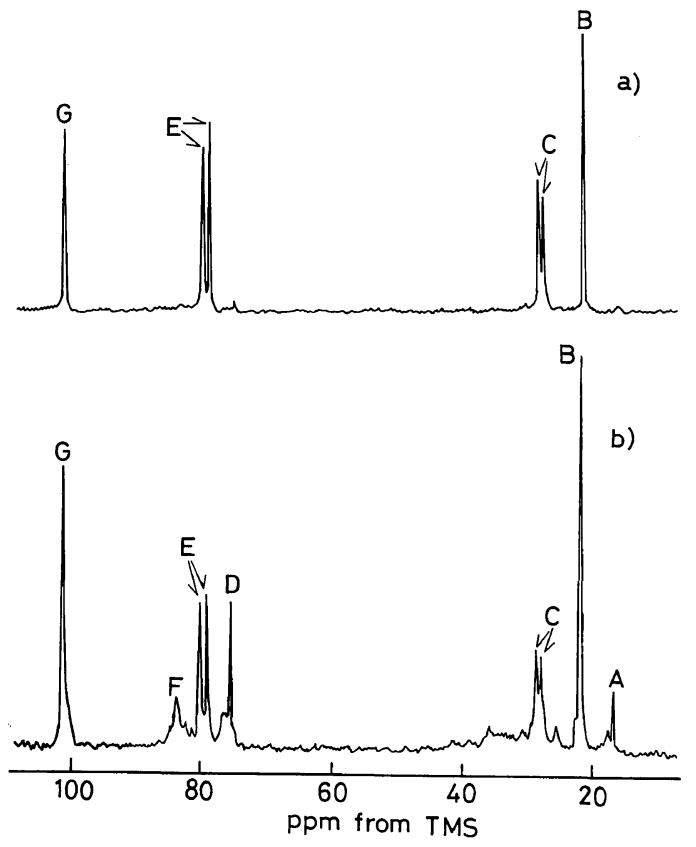

Figure 3. ${ }^{13} \mathrm{C}$ NMR spectra of poly(acetaldehyde divinyl acetal). a) Sample: Table II, run No. $1.27 \mathrm{wt} \%$ in $\mathrm{C}_{6} \mathrm{D}_{6}$ at $75^{\circ} \mathrm{C}$; accumulation, 1000 scans. b) Sample: polymer obtained in $\mathrm{C}_{6} \mathrm{H}_{6}$ at $70^{\circ} \mathrm{C}$ and at $[\mathrm{M}]=$ $1.5 \mathrm{moll}^{-1} .28 \mathrm{wt} \%$ in $\mathrm{C}_{6} \mathrm{D}_{6}$ at $75^{\circ} \mathrm{C}$; accumulation, 2000 scans.

nomer concentration at $-10^{\circ} \mathrm{C}$ gives a simple spectrum (Figure 3a) that indicates the nearly exclusive presence of the main structural unit VII: B, acetal methyl carbon; C exocyclic methylene carbon: $\mathrm{E}$, endocyclic methine carbon; $\mathrm{G}$, acetal methine carbon. Peaks $\mathrm{C}$ and $\mathrm{E}$ are split due to the two modes of connection of the structural unit as mentioned before. In contrast, the polymer obtained with a low monomer concentration at $70^{\circ} \mathrm{C}$ (Figure $3 \mathrm{~b}$ ) gave additional peaks ( $\mathrm{A}, \mathrm{D}$, and $\mathrm{F}$ ) suggesting the presence of the branched structure VIII. The presence of the trans ring units IX and $\mathbf{X}$ was not clear in this spectrum, since peaks due to the trans ring units were close to those of VIII. However, the ${ }^{1} \mathrm{H}$ NMR data (Figure 2b) point to their presence.

\section{Poly(acetone divinyl acetal)}

Table III contains the polymerization results 
Table III. Radical polymerization of acetone divinyl acetal

\begin{tabular}{|c|c|c|c|c|c|}
\hline \multirow{2}{*}{$\begin{array}{l}\text { Run } \\
\text { No. }\end{array}$} & $\begin{array}{l}\text { Polymn. } \\
\text { temp }\end{array}$ & AIBN & $\begin{array}{c}\text { Polymn. } \\
\text { time }\end{array}$ & Conversion & \multirow{2}{*}{$M_{n}$} \\
\hline & ${ }^{\circ} \mathrm{C}$ & $\mathrm{moll}^{-1}$ & $\mathrm{~h}$ & $\%$ & \\
\hline 1 & -10 & $5 \times 10^{-2}$ & 7.0 & 5.0 & 9000 \\
\hline 2 & 10 & $2 \times 10^{-1}$ & 0.6 & 6.3 & 8100 \\
\hline 3 & 30 & $5 \times 10^{-2}$ & 0.4 & 9.3 & 13000 \\
\hline 4 & 50 & $2 \times 10^{-2}$ & 16.0 & 8.7 & 48000 \\
\hline 5 & 70 & $2 \times 10^{-2}$ & 1.5 & 9.9 & 54000 \\
\hline
\end{tabular}

${ }^{\mathrm{a}}[\mathrm{M}]=5.0 \mathrm{moll}^{-1}$. Solvent, toluene for run 1 and benzene for runs $2-5$.

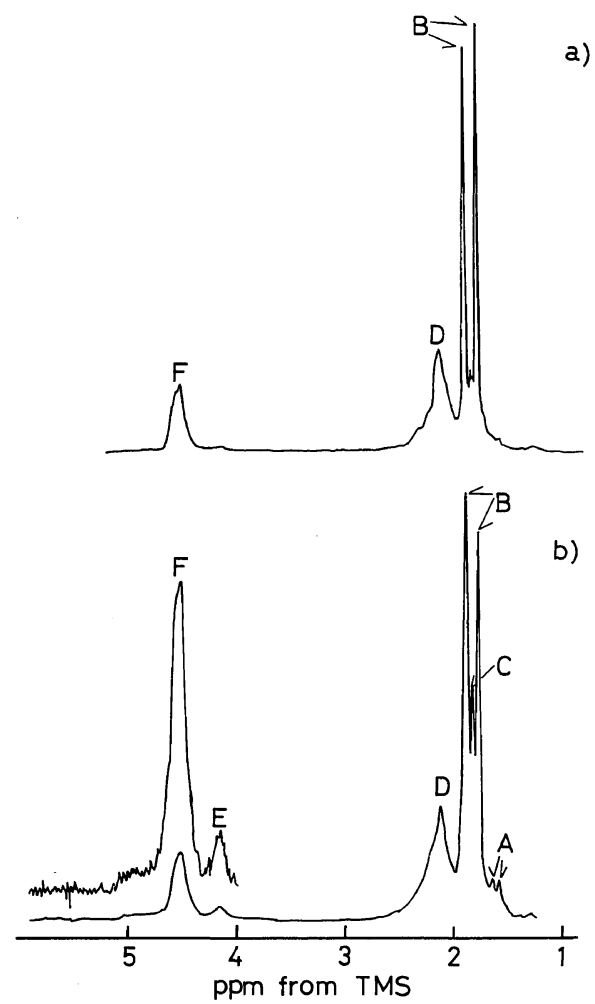

Figure 4. ${ }^{1} \mathrm{H}$ NMR spectra of poly(acetone divinyl acetal). a) Sample: Table III, run No. $1.3 \mathrm{w} / \mathrm{v} \%$ in $\mathrm{C}_{6} \mathrm{D}_{6}+o-\mathrm{C}_{6} \mathrm{H}_{4} \mathrm{Cl}_{2}$ at $140^{\circ} \mathrm{C}$; accumulation, 64 scans. b) Sample: Table III, run No. 5. $3 \mathrm{w} / \mathrm{v} \%$ in $\mathrm{C}_{6} \mathrm{D}_{6}+o$ $\mathrm{C}_{6} \mathrm{H}_{4} \mathrm{Cl}_{2}$ at $140^{\circ} \mathrm{C}$; accumulation, 64 scans.

of $2 \mathrm{CH}_{3}$-DVA at several temperatures. The molecular weights $(8000-50000)$ are greater than those of the other two polymers. Figure 4 shows ${ }^{1} \mathrm{H}$ NMR spectra of the polymer. The following structural units are conceivable.

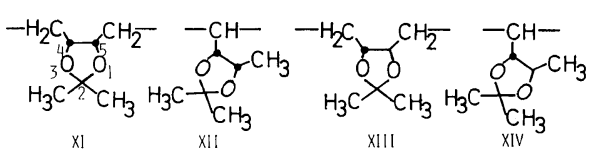

Spectral comparisons with the model compounds again suggest the following assignments

peak A (doublet), $1.62 \mathrm{ppm} ; 5-\mathrm{CH}_{3}$ proton in XII.

peak B (doublet), $1.82 \mathrm{ppm}$; acetal $\mathrm{CH}_{3}$ proton in XI and XII.

peak C, 1.82 ppm; acetal $\mathrm{CH}_{3}$ in XIII.

peak D, 2.13 ppm; exocyclic methylene and methine protons of all the units.

peak E, 4.14 ppm; methine proton at the 4 and 5 positions in XIII.

peak F, $4.50 \mathrm{ppm}$; methine proton at the 4 and 5 positions in $\mathbf{X I}$ and $\mathbf{X I I}$.

As indicated in the preceding section, the polymer spectrum is simpler at low temperatures than at high temperatures. The spectrum of a low-temperature polymer (Figure 4a) again indicates the polymer to be composed of the main structure almost exclusively. Other structural units become involved at high polymerization temperatures. The corresponding ${ }^{13} \mathrm{C}$ NMR spectra are given in Figure 5. The polymer obtained at $-10^{\circ} \mathrm{C}$ gives a simple spectrum (Figure 5a) which is consistent with the exclusive presence of structure XI: B (26.2 ppm), acetal $\mathrm{CH}_{3} ; \mathrm{C}$ (doublet, $26.5 \mathrm{ppm}$ ), exocyclic $\mathrm{CH}_{2}$ (meso and racemic forms); D (28.9 ppm), acetal $\mathrm{CH}_{3} ; \mathrm{G}$ (doublet, 78.2 ppm), ring $\mathrm{CH}$ (meso and racemic forms); $\mathbf{J}$ (107.6 ppm), acetal C. The polymer prepared at $70^{\circ} \mathrm{C}$ possesses peaks assignable to structure XII (A, F, H and I) (Figure 5b). The presence of the trans ring units XIII and XIV cannot be proved definitely; however, the splitting of peak $\mathrm{J}$ may be ascribed to these structures.

\section{Cyclization Process}

The cyclization of the growing radicals pro- 


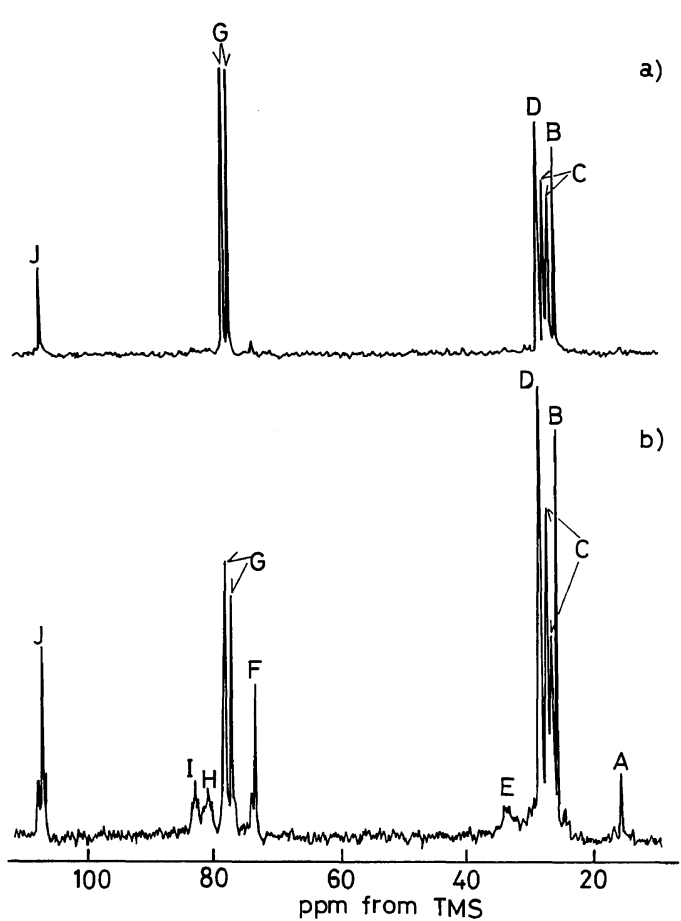

Figure 5. ${ }^{13} \mathrm{C}$ NMR spectra of poly(acetone divinyl acetal). a) Sample: Table III, run No. $1.15 \mathrm{wt} \%$ in $\mathrm{C}_{6} \mathrm{D}_{6}$ at $90^{\circ} \mathrm{C}$; accumulation, 3000 scans. b) Sample: polymer obtained in $\mathrm{C}_{6} \mathrm{D}_{6}$ at $70^{\circ} \mathrm{C}$ and at $[\mathrm{M}]=2.5 \mathrm{moll}^{-1}$. $28 \mathrm{wt} \%$ in $\mathrm{C}_{6} \mathrm{D}_{6}$ at $75^{\circ} \mathrm{C}$; accumulation, 1500 scans.

duces either the cis or trans ring as expressed by eq 1 .

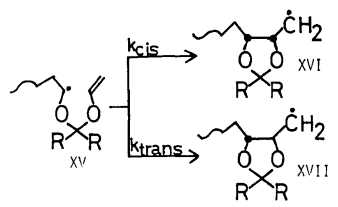

The relative ease of the $k_{c i s}$ and $k_{\text {trans }}$ processes in the case of DVF is equal to the ratio of the cis ring structures (I, II and V) and the trans ring structures (III, IV, and VI). In the ${ }^{1} \mathrm{H}$ NMR spectra of poly(DVF), the acetal proton peaks of structures I-VI are located at 4.5-5.0 ppm. ${ }^{11}$ The peaks at 4.63 and 4.80 ppm are assigned to the cis-syn proton of I, II, and $\mathbf{V}$ and to the cis-anti proton of I, II, and $\mathbf{V}$, respectively. The acetal protons of the trans

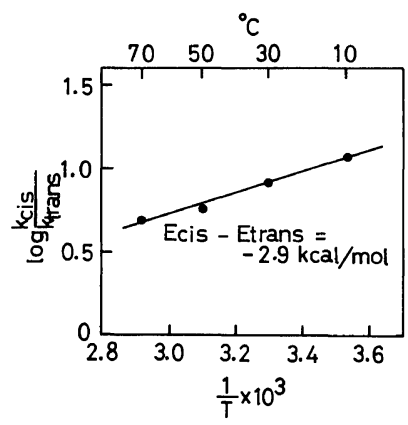

Figure 6. The relative activation energy of the cis and trans cyclizations in the polymerization of divinyl formal. Polymerization conditions: $\mathrm{C}_{6} \mathrm{H}_{6}$ solvent, $[\mathrm{M}]=$ $2.5 \mathrm{moll}^{-1}$.

ring are present at $4.67 \mathrm{ppm}$ (structures IV and VI) and at $4.86 \mathrm{ppm}$ (structure III). The ratio of the cis and trans rings are calculated from the relative peak area. The temperature dependence of the cis/trans ratio is given in Figure 6 in the form of Arrhenius plots. The difference in activation energy $\left(E_{\text {cis }}-E_{\text {trans }}\right)$ determined from the slope is $-2.9 \mathrm{kcal} \mathrm{mol}^{-1}$.

Similar analyses could not be conducted for poly $\left(\mathrm{CH}_{3}\right.$-DVA) and poly $\left(2 \mathrm{CH}_{3}\right.$-DVA), since the acetal protons are not separated in their ${ }^{1} \mathrm{H}$ NMR spectra.

\section{Isomerization vs. Monomer Addition}

The cyclized radical either isomerizes by hydrogen abstraction or adds a monomer molecule (eq 2).

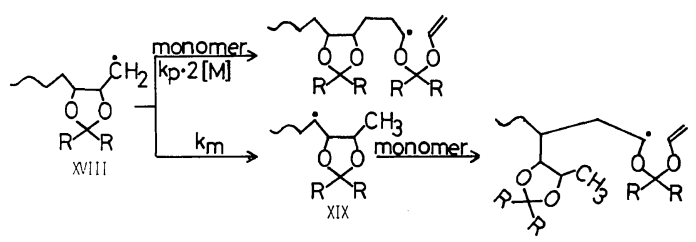

Ring stereochemistry could not be taken into consideration in this analysis, since the content of the trans rings is small and the respective NMR peaks are often overlapping. Thus, the results obtained are largely applicable to the cis ring units.

In the case of DVF polymer, the ${ }^{13} \mathrm{C}$ NMR 
peak of the ring methine in structure $\mathbf{I}$ appears at $77-78 \mathrm{ppm}$ and that of the methyl in structure II is located at $14 \mathrm{ppm}$. The terminal structure $\mathbf{V}$ can contribute to the latter peak; however, the amount of $\mathbf{V}$ is very small if at all, since the molecular weights of the polymers are 5000 to 14000 .

In the case of the least isomerized poly(DVF) (Figure 1), the relative peak areas of the acetal carbon, the ring methine, and the main-chain methylene are $1: 2.1: 1.8$. The area ratio of the ring-methine and main-chain methylene is $1.0: 1.0$ for a highly isomerized poly(DVF). The relative peak area of the ring methine and the acetal methyl is $1.8: 1$ (peaks $\mathrm{E}$ and $\mathrm{B}$ of Figure 3a) in the case of poly $\left(\mathrm{CH}_{3}-\right.$ DVA), and that of the ring methine and the acetal methyl is 2.0:2.0 (peaks $\mathrm{G}$ and $\mathrm{C}$ of Figure 5a) in the case of poly $\left(2 \mathrm{CH}_{3}\right.$-DVA). These data clearly show that the nuclear Overhauser effect is virtually the same (within $\pm 10 \%$ ) for the $\mathrm{CH}, \mathrm{CH}_{2}$, and $\mathrm{CH}_{3}$ carbons of these polymers and that the structural variation of the polymers can be discussed on the basis of the ${ }^{13} \mathrm{C}$ NMR data.

Thus, the ratio of $\mathbf{I}$ and $\mathbf{I I}$ in poly(DVF) is estimated very simply by comparing the heights or the areas of the methine and methyl peaks. The mole fraction of the isomerized structure, $f_{\mathrm{m}}=\mathbf{I I} /(\mathbf{I}+\mathbf{I I})$ is thus obtained. Similar estimations were performed for poly $\left(\mathrm{CH}_{3}\right.$-DVA) and poly $\left(2 \mathrm{CH}_{3}\right.$-DVA). The influence of monomer concentration on $f_{\mathrm{m}}$ is given in Figure 7. In all three systems, $f_{\mathrm{m}}$ decreases with increasing monomer concentration, as anticipated from eq 2 . Introduction of the methyl group at the acetal carbon lowers the extent of the isomerization.

The temperature dependence of these processes can be evaluated from the ${ }^{13} \mathrm{C}$ NMR spectra of the polymers obtained at different temperatures (Tables I, II, and III). The rates of simple propagation and hydrogen migration (isomerization) are given, respectively, by

$$
R_{\mathrm{p}}=k_{\mathrm{p}}[\mathrm{M} \cdot] 2[\mathrm{M}]
$$

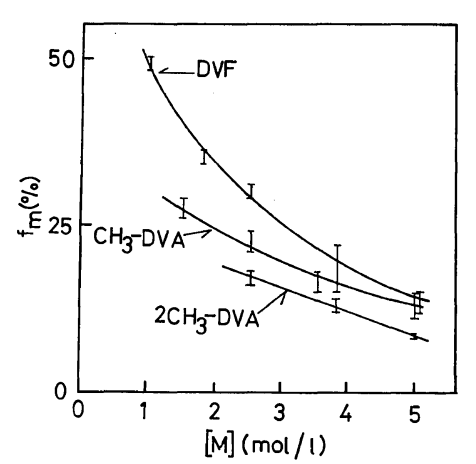

Figure 7. Influence of monomer concentration on the mole fraction of the isomerized structures. Polymerization condition: $\mathrm{C}_{6} \mathrm{H}_{6}$ solvent, $70^{\circ} \mathrm{C}$.

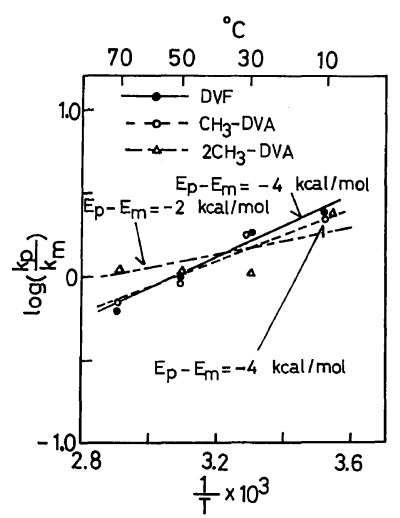

Figure 8. Relative activation energy of the intramolecular hydrogen abstraction and intermolecular propagation. Polymerization conditions: $\mathrm{C}_{6} \mathrm{H}_{6}$ solvent, $[\mathrm{M}]=2.5 \mathrm{moll}^{-1}$ for divinyl formal; $\mathrm{C}_{6} \mathrm{H}_{6}$ solvent, $[\mathrm{M}]=5.0 \mathrm{moll}^{-1}$ for acetaldehyde divinyl acetal and acetone divinyl acetal.

$$
R_{\mathrm{m}}=k_{\mathrm{m}}[\mathrm{M} \cdot]
$$

where $\mathbf{M} \cdot$ is the cyclized radical.

Therefore,

$$
k_{\mathrm{p}} / k_{\mathrm{m}}=\frac{1}{2[\mathrm{M}]} \cdot \frac{R_{\mathrm{p}}}{R_{\mathrm{m}}}
$$

Figure 8 shows Arrhenius plots for $k_{p} k_{m}$. The slopes correspond to differences in the apparent activation energy between simple propagation and isomerization $\left(E_{\mathrm{p}}-E_{m}\right)$, and are always negative, being $-4 \mathrm{kcal} \mathrm{mol}^{-1}$ for DVF and $\mathrm{CH}_{3}$-DVA and ca. $-2 \mathrm{kcal} \mathrm{mol}^{-1}$ for $2 \mathrm{CH}_{3}$-DVA. Although the plots for $2 \mathrm{CH}_{3}$ - 
DVA are scattered, the slope is certainly less than the others. Di-methyl substitution at the acetal carbon thus renders the $k_{p}$ process energetically less favored. That is hydrogen migration is energetically less favored in the case of DVF and $\mathrm{CH}_{3}$-DVA. However, since the $k_{p} / k_{m}$ values themselves are not very different among the monomers, the frequency factor is favorable for the isomerization process of the cyclized DVF and $\mathrm{CH}_{3}$-DVA radicals.

The conformation of 1,3-dioxolanes has been studied by Lemineux and coworkers. ${ }^{12}$ When there is no methyl substituent at the acetal carbon, the five-membered ring assumes an eclipsed form. The gem-dimethyl derivative,
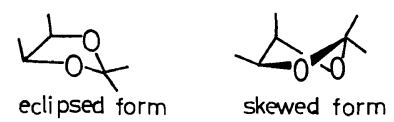

in contrast, assumes a skewed form. The dihedral angle of the $c i s-4,5$-hydrogens is greater in the skewed form than in the eclipsed form. The distance between the exocyclic methylene radical and main chain methylene hydrogen in the cis cyclized radical of $2 \mathrm{CH}_{3}$-DVA may thus be greater than the corresponding distance in the cyclized radical of DVF. The hydrogen atom transfer would then be more favored in the DVF radical than in the $2 \mathrm{CH}_{3}$ DVA radical.

\section{Reactivity of Cyclized Radicals}

The relative reactivities of cyclized radical (without isomerization) XVIII and the subsequently isomerized radical XIX can be inferred from molecular weights of the polymers. The polymerizations of the three monomers were carried out at $70^{\circ} \mathrm{C}$ in benzene at different monomer concentrations. The relations between the initial monomer concentration and the number-average molecular weight of the polymers are illustrated in Figure 9. The slope of the double logarithmic plots is 1.2 for DVF and 1.0 for $\mathrm{CH}_{3}$-DVA and $2 \mathrm{CH}_{3}$-DVA. At this polymerization temperature $\left(70^{\circ} \mathrm{C}\right)$, the

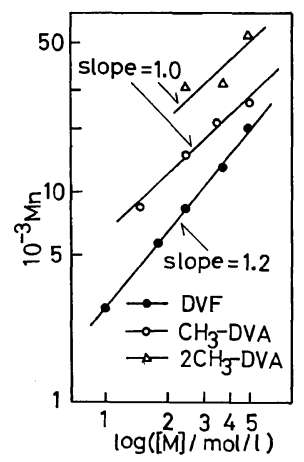

Figure 9. Dependence of molecular weight on monomer concentration. Polymerization conditions: $\mathrm{C}_{6} \mathrm{H}_{6}$ solvent, $70^{\circ} \mathrm{C},[\mathrm{AIBN}]=2 \times 10^{-2} \mathrm{moll}^{-1}$.

intermolecular propagation occurs from both the cyclized radical XVIII and its isomerized derivative XIV. Propagation from the latter decreases with increasing monomer concentration. The observed slopes close to unity imply the reactivities of the radicals involved in the propagation to be uniform, as in typical homopolymerization. This means that the cyclized radical and isomerized radical exhibit close reactivities.

The influence of monomer concentration on the rate of cyclopolymerization has been reported. Minoura and Mitoh ${ }^{13}$ found the 1.5th order dependence at $[\mathrm{M}]=0.9-2.7 \mathrm{~mol}^{-1}$ and the 2.2 th order dependence at $[\mathrm{M}]=2.7$ mol $1^{-1}$ in the polymerization of DVF in benzene at $50^{\circ} \mathrm{C}$. Smets et al. ${ }^{14}$ obtained the order of 3 in the cyclopolymerization of methacrylic anhydride. The reason why the orders are high in these cases is not clear. The microviscosity effect may be responsible in some cases. At any rate, the present systems are quite normal, and no kinetic anomaly is expected from the available data.

\section{Concluding Remarks}

The propagation scheme of divinyl acetals is given by eq 1 and eq 2 . The overall rate of polymerization appears to decrease with increasing methyl substitution at the acetal carbon: DVF $>\mathrm{CH}_{3}$-DVA $>2 \mathrm{CH}_{3}$-DVA. The 
polymers possess fairly uniform structures: $c i s$ 1,3-dioxolane rings are the major structural units, and the six-membered rings and uncyclized units are excluded. The dioxolane structural units are present in the pendent group due to radical isomerization. The formation of the pendent unit could be lowered by lowering the polymerization temperature and increasing the monomer concentration. It is thus, expected that highly regular cisdioxolane polymers are obtainable in the cyclopolymerization of divinyl acetals by the proper choice of conditions.

\section{REFERENCES}

1. C. Aso and A. Ushio, Makromol. Chem., 100, 100 (1976).

2. M. Guaita, C. Camino, and L. Trossarelli, Makromol. Chem., 131, 237 (1970).

3. T. Kunitake and M. Tsukino, Makromol. Chem.,
177, 303 (1976).

4. M. Tsukino and T. Kunitake, Macromolecules, 12, 387 (1979).

5. S. R. Johns, R. I. Willing, S. Middleton, and A. K. Ong, J. Macromol. Sci. Chem., A10, 875 (1976).

6. J. E. Lancaster, L. Baccei, and H. P. Panzer, $J$. Polym. Sci., Polym. Lett. Ed., 14, 549 (1976).

7. K. Urushido, Y. Takizawa, A. Matsumoto, and M. Oiwa, Makromol. Chem., Rapid Commun., 4, 21 (1983).

8. A. Matsumoto, T. Kitamura, and M. Oiwa, Makromol. Chem., Rapid Commun., 2, 638 (1981).

9. T. Kodaira, F. Aoyama, K. Morishita, M. Tsuchida, and S. Nogi, Kobunshi Ronbunshu, 31, 682 (1974).

10. M. Tsukino and T. Kunitake, Polym. J., 11, 437 (1979).

11. M. Tsukino and T. Kunitake, ACS Symposium Series, No. 195, 73 (1982).

12. R. U. Lemineux, J. D. Stevens, and R. R. Fraster, Can. J. Chem., 40, 1955 (1962).

13. Y. Minoura and M. Mitoh, J. Polym. Sci., 52, 189 (1961).

14. G. Smets, P. Hous, and N. Deval, J. Polym. Sci., A, 2, 4825 (1964). 